\title{
Komputerowa analiza zwarcia w grupie osób z akromegalią
}

\author{
Computer analysis of occlusion in patients with acromegaly \\ ${ }_{1}^{1}$ Oddział Otolaryngologii i Onkologii Laryngologicznej z Pododdziałem Chirurgii Szczękowej, \\ Szpital Uniwersytecki nr 2 im. Jana Biziela w Bydgoszczy \\ ${ }^{2}$ Klinika Gerostomatologii i Patologii Jamy Ustnej, Uniwersytet Medyczny im. Karola Marcinkowskiego w Poznaniu
}

DOI: http://dx.doi.org/10.20883/df.2017.18

\begin{abstract}
Streszczenie
Wstęp. Charakterystyczne w przebiegu akromegalii powiększenie żuchwy może w znaczący sposób wpłynąć na funkcjonowanie narządu żucia.

Cel. Komputerowa analiza zwarcia, przeprowadzona aparatem T-scan III w grupie osób z akromegalią.

Materiał i metody. Grupę badaną stanowiły 22 osoby ze zdiagnozowaną, czynną akromegalią, natomiast grupę kontrolną 22 zdrowe osoby z pełnym uzębieniem. Analizę przeprowadzono w oparciu o parametry mierzone aparatem T-scan III Tekscan.

Wyniki. Średnie wartości różnic w rozkładzie sił zwarciowych między prawą a lewą stroną różnią się w sposób istotny statystycznie w grupie z akromegalią. Obserwujemy też znaczące przeniesienie sił na przedni odcinek łuku zębowego. Czas okluzji OT jest wydłużony powyżej normy, a środek sił zwarciowych jest położony poza obszarem referencyjnym. Wnioski. Komputerowa analiza zwarcia u pacjentów z akromegalią wykazuje zmiany kontaktów między zębami przeciwstawnymi oraz zmiany rozkładu i zbalansowania sił żucia.
\end{abstract}

Słowa kluczowe: akromegalia, T-scan, komputerowa analiza zwarcia.

\begin{abstract}
Introduction. The characteristically enlarged mandible associated with acromegaly may have an influence on the function of the stomatognathic system.

Aim. The aim of the study was to evaluate occlusion using a T-scan III occlusal analysis system in patients with acormegaly. Material and Methods. The study group was 22 people diagnosed with active acromegaly; and the control group comprised 22 healthy individuals with full dentition. The analysis was conducted using parameters measured with the T-scan III Tekscan occlusal analysis system.

Results. The average values for the differences between the right and left side of the dental arch were statistically different in the group with acromegaly. A significant redistribution of occlusal forces to the anterior part of the dental arch was also observed. The occlusal time (OT) was longer than standard and the occlusal centre of force was located outside the reference area.

Conclusions. The occlusal analysis system showed changes in the contacts between opposing teeth as well as in the distribution and balance of occlusal forces in comparison with the control group.
\end{abstract}

Keywords: acromegaly, T-scan, occlusal analysis system.

\section{Wstęp}

Akromegalia jest rzadką, przewlekłą chorobą endokrynologiczną, która spowodowana jest nadmiernym wydzielaniem hormonu wzrostu (somatotropiny, growth hormone, $\mathrm{GH}$ ). Działa on na tkanki i narządy nie tylko bezpośrednio, ale także w sposób pośredni poprzez polipeptydowe czynniki wzrostu zwane somatomedynami, w tym głównie poprzez insulinopodobny czynnik wzrostu-1 (IGF-1) [1]. U ponad 95\% chorych przyczyną akromegalii jest obecność łagodnego gruczolaka w przednim płacie przysadki [2, 3]. Zarówno sam hormon wzrostu, jak i IGF-1 stymulują proliferację osteoblastów, przyczyniając się do zmian w obrębie tkanki kostnej w przebiegu choroby [4]. Stwier- dzono, iż w aktywnej fazie choroby przebudowa kości jest wzmożona, z przewagą adsorpcji [5, 6]. Nierównomierny wzrost kości spowodowany jest utratą potencjału wzrostowego u osób dorosłych w większości miejsc w obrębie szkieletu oraz odmienną budową kości w różnych jego częściach. W akromegalii wyraźniejsze jest stymulujące działanie hormonu wzrostu i substancji pośrednich na rozbudowę kości w obrębie istoty zbitej i w miejscach występowania tkanki chrzęstnej oraz w okostnej. Niekontrolowany rozrost tkanek miękkich i kości pod wpływem GH i IGF-1 prowadzi do charakterystycznych zmian w obrębie czaszki. $\mathrm{Na}$ podstawie analiz cefalometrycznych telerentgeno- 
gramów bocznych głowy wykazano, iż zmiany dotyczą zarówno twarzoczaszki, jak i mózgoczaszki [7]. Kostne powikłania w przebiegu akromegalii są bardzo dotkliwe dla pacjentów, gdyż są nieodwracalne. Szczególnie charakterystyczne są zmiany w obrębie żuchwy, która ulega powiększeniu i wysunięciu. Rozrost jest wyraźniejszy w obrębie gałęzi żuchwy niż w obrębie trzonu. Dla odmiany pozycja i rozmiar szczęki pozostają niezmienione. W związku z tym obserwujemy klinicznie masywną, wystającą ku przodowi żuchwę. Wpływa to nie tylko na zaburzenia wyglądu, ale także na znaczne ograniczenie funkcji narządu żucia.

Zmiana relacji pomiędzy szczęką a żuchwą u pacjentów $z$ akromegalią zachęciła do sprawdzenia, czy w istotny sposób zmianie ulegają także kontakty między zębami przeciwstawnymi oraz czy zmienia się rozkład sił żucia oraz ich zbalansowanie. W tym celu zastosowano aparat do komputerowej analizy zwarcia T-scan III. System ten stał się wartościowym narzędziem diagnostycznym, które pomaga lekarzowi w analizie zwarcia i odnalezieniu zaburzeń funkcji układu stomatognatycznego. Prawidłowa okluzja zapewnia równomierną dystrybucję sił międzyzębowych w obrębie łuku. Siły powinny działać wzdłuż długiej osi zęba i być równomiernie zbalansowane między prawą a lewą stroną [8].

\section{Cel}

Celem pracy jest komputerowa analiza zwarcia, przeprowadzona aparatem T-scan III w grupie osób z akromegalią oraz porównanie otrzymanych wyników z grupą osób z zachowanym pełnym uzębieniem, bez zaburzeń w obrębie narządu żucia.

\section{Materiał i metody}

Grupę badaną stanowiły 22 osoby ze zdiagnozowaną, czynną akromegalią, leczone w Klinice Endokrynologii, Przemiany Materii i Chorób Wewnętrznych Uniwersytetu Medycznego im. Karola Marcinkowskiego w Poznaniu. Z badania zostały wyłączone

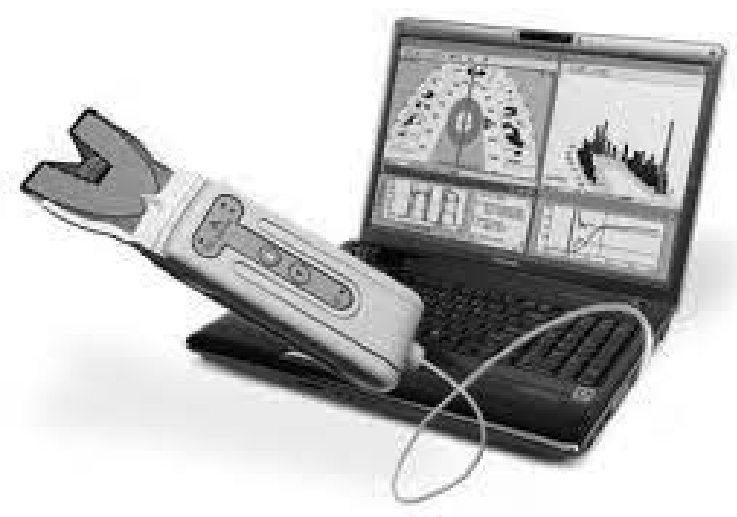

Rycina 1. System T-scan III firmy Tekscan

Figure 1. System T-scan III by Tekscan.

osoby bezzębne, które nie użytkowały uzupełnień protetycznych, zapewniających prawidłowe warunki zwarcia. Grupę kontrolną dla tego badania stanowiły 22 zdrowe osoby z pełnym uzębieniem (z pominięciem zębów mądrości) (Tabela 1).

Ocenę rozkładu kontaktów zwarciowych przeprowadzono w oparciu o badanie okluzji w pozycji centralnej $z$ zastosowaniem aparatu do komputerowej analizy zwarcia T-scan III (Tekscan) (Rycina 1).

Badanie u każdego pacjenta przeprowadzono, zgodnie z zaleceniami, w pozycji siedzącej z lekko odgiętą ku tyłowi, podpartą głową [9]. Po wprowadzeniu sensora między tuki zębowe proszono pacjenta o mocne zaciśnięcie zębów, jednocześnie rejestrując maksymalną siłę nacisku na czujnik oraz czas od momentu pierwszego kontaktu do uzyskania maksimum siły. Wykorzystano technike „3-closure recording technique”, opisaną przez Qadeer i in. [10], w której pacjent zagryza trzykrotnie zęby na 2 sekundy, co daje duże prawdopodobieństwo uzyskania przynajmniej jednego zamknięcia z maksymalną siłą. Spośród uzyskanych pomiarów wybierano do analizy jeden skan, na którym uzyskano maksymalną siłę kontaktów. Przed badaniem każdego pacjenta urządzenie było kalibrowane pod względem czułości. Konieczne było dostosowanie wirtualnego łuku do

Tabela 1. Rozkład liczbowy i procentowy badanych aparatem T-scan III z podziałem na płeć i wiek

Table 1. The study and the control group accordingly to sex and age

\begin{tabular}{|c|c|c|c|c|c|c|c|}
\hline \multirow{2}{*}{ Parametry } & \multicolumn{3}{c|}{ Grupa badana } & \multicolumn{3}{c|}{ Grupa kontrolna } \\
\cline { 3 - 8 } & $\mathrm{N}$ & Kobiety & Mężczyźni & Całkowita & Kobiety & Mężczyźni & Całkowita \\
\hline \multicolumn{2}{|c|}{} & 16 & 6 & 22 & 13 & 9 & 22 \\
\hline \multirow{3}{*}{ W } & 72,7 & 27,3 & 100 & 59,1 & 40,9 & 100 \\
\hline \multirow{3}{*}{ Wiek } & Minimum & 29 & 35 & 29 & 22 & 22 & 22 \\
\cline { 2 - 8 } & Maximum & 68 & 66 & 68 & 56 & 60 & 60 \\
\cline { 2 - 8 } & Średnia & 53,1 & 50,7 & 52,5 & 29,3 & 30,3 & 29,7 \\
\cline { 2 - 8 } & SD & 11,8 & 11,7 & 11,6 & 5,6 & 5,6 & 5,7 \\
\hline
\end{tabular}




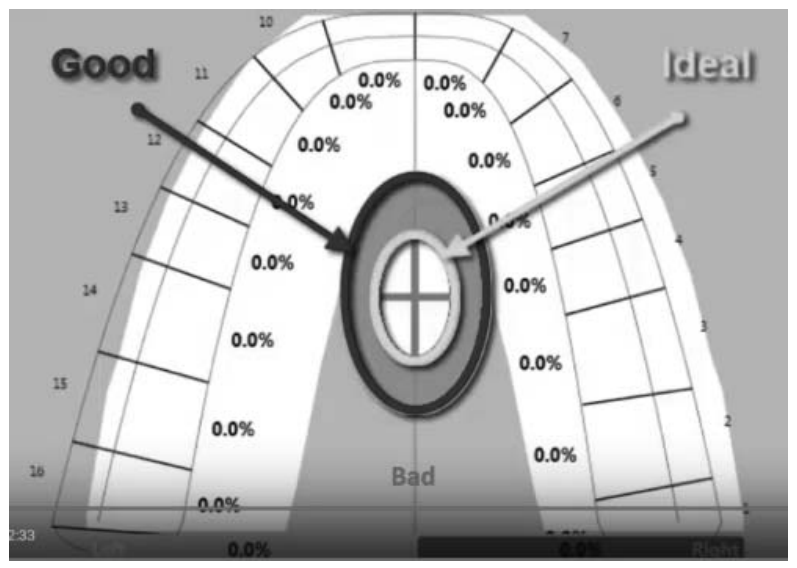

Rycina 2. Położenie markera wskazującego środek sił zwarciowych

Figure 2. Location of mark in the center of occlusal forces

wymiarów pacjenta na podstawie indywidualnej szerokości centralnego siekacza. W trakcie badań analizowano procentowy udział kontaktów okluzyjnych prawej i lewej strony oraz rozkład sił pomiędzy przodem a tyłem. Dla porównań z grupą kontrolną stosowano średnią różnicę między nimi, wyrażoną w procentach. Skorzystano również z funkcji pomiaru czasu okluzji (OT - occlusal time), czyli czasu od momentu pierwszego kontaktu do maksymalnego zaguzkowania, który w warunkach fizjologii nie powinien przekraczać
0,2 s. U każdego pacjenta określono również środek sił zwarciowych (COF), określany na podstawie położenia markera lokalizującego wypadkowy moment wszystkich sił działających podczas kontaktu zwarciowego. W zależności od jego umiejscowienia w stosunku do wyznaczonej przez program eliptycznej tarczy COF TARGET określano środek sił zwarciowych jako prawidłowy (,ideal” lub „good”) albo nieprawidłowy (marker położony poza zaznaczonym obszarem) (Rycina 2).

W trakcie analizy określono również maksymalne i minimalne obciążenie procentowe pojedynczego zęba w maksymalnym zaguzkowaniu. Wszystkie wyniki grupy badanej porównano z wynikami otrzymanymi w grupie kontrolnej. Do analizy statystycznej wykorzystany został program Statistica 10.0 (StatSoft Inc., 2011).

\section{Wyniki}

Analiza procentowego udziału kontaktów okluzyjnych prawej i lewej strony w obu grupach nie wykazała istotnych statystycznie różnic (Tabela 2).

Natomiast średnia różnica między nimi była istotnie statystycznie większa w grupie badanej (Tabela 3).

W analizie procentowego udziału kontaktów okluzyjnych przedniego i tylnego odcinka łuku

Tabela 2. Procentowy udział kontaktów okluzyjnych prawej i lewej strony

Table 2. Percentage participation of left and right occlusal contacts

\begin{tabular}{|l|c|c|c|c|c|c|c|c|c|c|}
\hline \multirow{2}{*}{ Zmienna } & \multicolumn{4}{|c|}{ Grupa kontrolna } & \multicolumn{5}{c|}{ Grupa badana } \\
\cline { 2 - 25 } & Średnia & SD & Mediana & Max. & Min. & Średnia & SD & Mediana & Max. & Min. \\
\hline Prawa [\%] & 52,5 & 6,7 & 49,9 & 67,7 & 41,2 & 52,8 & 17,4 & 49,9 & 95,5 & 28,7 \\
\hline Lewa [\%] & 47,5 & 6,6 & 50,1 & 58,7 & 32,3 & 47,9 & 17,1 & 52,3 & 71,3 & 4,5 \\
\hline P & \multicolumn{4}{|c|}{0,2172} \\
\hline
\end{tabular}

Tabela 3. Średnia wartość różnic między stronami w grupie kontrolnej i badanej

Table 3. Average value of differences between sides in study and control group

\begin{tabular}{|l|c|c|c|c|c|c|c|c|c|}
\hline \multirow{2}{*}{ Zmienna } & \multicolumn{5}{|c|}{ Grupa kontrolna } & \multicolumn{5}{c|}{ Grupa badana } & \multirow{2}{*}{ P } \\
\cline { 2 - 10 } & Średnia & SD & Max. & Min. & Średnia & SD & Max. & Min. & \\
\hline $\begin{array}{l}\text { Prawa-Lewa } \\
\text { (średnia różnica) [\%] }\end{array}$ & 10,2 & 9,8 & 35,4 & 0,0 & 27,3 & 21,6 & 91,0 & 1,8 & 0,0006 \\
\hline
\end{tabular}

Tabela 4. Rozkład procentowy kontaktów okluzyjnych między przodem a tyłem

Table 4. Distribution between anterior and posteriori part of dental arch

\begin{tabular}{|l|c|c|c|c|c|c|c|c|c|c|}
\hline \multirow{2}{*}{ Zmienna } & \multicolumn{4}{|c|}{ Grupa kontrolna } & \multicolumn{4}{c|}{ Grupa badana } \\
\cline { 2 - 13 } & Średnia & SD & Mediana & Max. & Min. & Średnia & SD & Mediana & Max. & Min. \\
\hline Przód [\%] & 36,5 & 10,5 & 35,1 & 61,2 & 16,2 & 72,4 & 25,3 & 81,9 & 100,0 & 28,9 \\
\hline Tył [\%] & 63,5 & 10,5 & 64,9 & 83,7 & 38,8 & 28,4 & 26,5 & 18,1 & 77,0 & 0,0 \\
\hline P & \multicolumn{4}{|c|}{0,0002} & & \multicolumn{5}{c|}{0,0030} \\
\hline
\end{tabular}


Tabela 5. Średnia różnica rozkładu sił między przodem a tyłem

Table 5. Average difference between force location between anterior and posteriori part

\begin{tabular}{|c|c|c|c|c|c|c|c|c|c|}
\hline \multirow{2}{*}{ Zmienna } & \multicolumn{4}{|c|}{ Grupa kontrolna } & \multicolumn{4}{|c|}{ Grupa badana } & \multirow{2}{*}{$P$} \\
\hline & Średnia & SD & Max. & Min. & Średnia & SD & Max. & Min. & \\
\hline $\begin{array}{l}\text { Przód-Tył } \\
\text { (średnia różnica) }\end{array}$ & 29,9 & 16,3 & 67,5 & 7,0 & 57,0 & 36,2 & 100,0 & 1,6 & 0,0172 \\
\hline
\end{tabular}

Tabela 6. Czas okluzji w grupie kontrolnej i badanej

Table 6. Occlusal time in study and control group

\begin{tabular}{|l|c|c|c|c|c|c|c|c|c|}
\hline \multirow{2}{*}{ Zmienna } & \multicolumn{4}{|c|}{ Grupa kontrolna } & \multicolumn{4}{c|}{ Grupa badana } & \multirow{2}{*}{ P } \\
\cline { 2 - 11 } & Średnia & SD & Max. & Min. & Średnia & SD & Max. & Min. & \\
\hline OT & 0,23 & 0,37 & 0,37 & 0,13 & 0,43 & 0,30 & 1,18 & 0,09 & 0,0072 \\
\hline
\end{tabular}

zębowego oraz w porównaniu średnich wartości różnic między nimi otrzymano następujące wyniki: zarówno w grupie kontrolnej, jak i w grupie badanej wykazano istotną statystycznie różnice między rozkładem procentowym między przednim a tylnym odcinkiem - przy czym przeniesienie siły okluzyjnej do przodu przeważało w grupie badanej, natomiast ku tyłowi w grupie kontrolnej (Tabela 4).

Średnia różnica rozkładu sił między przednim a tyInym odcinkiem łuku zębowego w obu grupach wykazywała znaczącą statystycznie różnicę (Tabela 5).

Program mierzy także czas okluzji (OT), czyli czas od moment pierwszego kontaktu do maksymalnej interkuspidacji. Daje on informację o tym, jak szybko i czy symultanicznie kontaktują się zęby podczas zwarcia. Według zaleceń czas ten nie powinien przekraczać $0,2 \mathrm{~s} w$ warunkach fizjologii [11]. Badając czas okluzji OT, wykazano istotną statystycznie różnicę pomiędzy jego długością w grupie kontrolnej i w grupie badanej, przy czym był on dłuższy w grupie badanej (Tabela 6).

W ocenie zrównoważenia zwarcia przydatna jest także opcja COF (Center of Force), która wyznacza graficznie środek siły zwarcia. Możliwe jest uwidocznienie toru, po którym się przemieszczał $w$ trakcie zwarcia, co pozwala na ocenę jego stabilności i poślizgu centrycznego. Określając COF położenie środka sił zwarciowych w kategoriach:

- GOOD - prawidłowy,

- BAD - położony poza obszarem wyznaczającym środek sił zwarciowych.

W grupie kontrolnej wszystkie osoby (100\%) charakteryzowały się położeniem środka sił zwarciowych w prawidłowym obszarze, co stanowi istotną statystycznie różnicę ( $p=0,0001)$ względem grupy badanej, w której większość pacjentów $(68,18 \%)$ charakteryzuje się położeniem środka sił zwarciowych poza tym obszarem (Tabela 7).
Tabela 7. Położenie środka sił zwarciowych COF w obszarze prawidłowym i poza nim w grupie badanej i kontrolnej

Table 7. Location of center of occlusal force COF in refernce location and outside in study and control group

\begin{tabular}{|l|c|c|c|}
\hline \multirow{2}{*}{ COF } & \multicolumn{3}{|c|}{$\begin{array}{c}\text { Podsumowująca tabela dwudzielcza: } \\
\text { częstości obserwowane }\end{array}$} \\
\cline { 2 - 4 } & $\begin{array}{c}\text { Grupa } \\
\text { badana }\end{array}$ & $\begin{array}{c}\text { Grupa } \\
\text { kontrolna }\end{array}$ & Razem \\
\hline Good & 7 & 22 & 29 \\
\hline$\%$ & $31,82 \%$ & $100,00 \%$ & \\
\hline Bad & 15 & 0 & 15 \\
\hline$\%$ & $68,18 \%$ & $0,00 \%$ & \\
\hline Ogół & 22 & 22 & 44 \\
\hline
\end{tabular}

\section{Dyskusja}

Badanie miało na celu analizę aktualnego stanu zwarcia u pacjentów z akromegalią (bez ingerencji leczniczej) i porównanie wyników z wynikami osób o pełnym uzębieniu, czyli z grupą o zachowanej w pełni funkcji żucia. Niespełnianie warunków prawidłowej okluzji wpływa negatywnie na czynność narządu żucia, stan stawów skroniowo-żuchwowych, a także może prowadzić do nieosiowego obciążania zębów. Warto zbadać, w jakim zakresie funkcja ta została upośledzona u pacjentów chorujących na akromegalię.

W pierwszej kolejności do analizy wykorzystano funkcję rozkładu procentowego kontaktów okluzyjnych. Możliwe było porównanie strony prawej i lewej oraz przodu (w zakres którego wchodził obszar obejmujący kły i siekacze) oraz tyłu (przedtrzonowce i trzonowce) w grupie badanej i kontroInej, a co ważniejsze także średnich różnic między grupami. Pomimo iż między stronami prawą i lewą nie wykazano istotnych statystycznie różnic w żadnej z grup, to średnia wartość różnicy między stronami w grupie kontrolnej wynosiła 10,2\%, natomiast w grupie osób z akromegalią 27,3\%. Otrzymane wyniki różnią się w sposób istotny sta- 
tystycznie $(p=0,0006)$, co wskazuje na predyspozycję grupy badanej do utraty stabilności i symetryczności rozkładu kontaktów okluzyjnych. Warto zwrócić uwagę na maksymalną wartość różnicy między stronami w grupie osób $z$ akromegalią, która wynosiła aż $91 \%$, co świadczy o przypadku zachowania funkcji układu stomatognatycznego tylko po jednej stronie. Odmienny rozkład kontaktów okluzyjnych i sił zgryzowych w badanej grupie wskazuje na brak stabilności. W konsekwencji może to powodować niekorzystne zmiany w układzie stomatognatycznym, takie jak przemieszczenia zębów poziome i pionowe, brak fizjologicznego napięcia w łuku zębowym, obecność węzłów urazowych i nieprawidłowych kontaktów. Brak symetrii w okluzji jest również powodem nieprawidłowej pracy mięśni żwaczowych [12]. Analiza procentowego udziału kontaktów okluzyjnych przodu i tyłu w obu grupach ukazuje wyraźną tendencję do przeniesienia siły okluzyjnej do przodu w grupie badanej. Przedni odcinek łuku - od kła do kła przyjmował w grupie badanej $72,4 \%$ całkowitej siły zwarcia, natomiast w grupie kontrolnej to tylny odcinek - przedtrzonowce i trzonowce - przyjmował większą siłę: $63,5 \%$. Różnica rozkładu sił między przodem a tyłem w obu grupach wykazywała więc znaczącą statystycznie różnicę między grupami $(p=0,0172)$. Analizując powyższe wyniki w oparciu o dostępne w piśmiennictwie dane można stwierdzić, że zróżnicowanie rozkładu sił w obrębie jamy ustnej jest szeroko opisywane. Wiadomo, iż najkorzystniejsze jest symetryczne rozłożenie sił pomiędzy stroną prawą a lewą, bo zapewnia stabilność. Natomiast jeśli chodzi o różnicę w rozkładzie pomiędzy przodem a tyłem, to w prawidłowych warunkach badacze opisują większy udział trzonowców w przyjmowaniu sił zgryzu. Taki rozkład siły w warunkach fizjologicznych wynika ze skurczu mięśni przywodzących żuchwę (mięśnie skroniowe, żwacze i skrzydłowe przyśrodkowe) oraz dodatkowo odpowiada lepszym warunkom zębów trzonowych na przyjęcie wyższych wartości siły. Zmiana obserwowana w grupie osób $z$ akromegalią może być związana $z$ utratą części uzębienia w odcinkach bocznych i znaczącego przeniesienia siły zwarcia ku przodowi, ale także ze zmianami morfologicznymi struktur żuchwy, powodującymi jej wysunięcie. Ścisły związek morfologii i funkcji w układzie stomatognatycznym sprawia, iż ilość uzębienia i warunki okluzyjne pełnią zasadniczą rolę $w$ regulacji napięcia $i$ funkcjonowania mięśni żucia, a co za tym idzie także w wielkości wyzwalanych sił żucia [13]. Warto zauważyć, iż w badanej grupie tylko 19,4\% pacjentów miało zachowane podparcie we wszystkich 4 strefach i zostało sklasyfikowanych jako grupa A, zgodnie z klasyfikacją wg Eichnera. Dodatkowo wysunięcie żuchwy obserwowane $\mathrm{w}$ przebiegu akromegalii prowadzić może do zgryzu prostego lub nawet nagryzu ujemnego, co prowadzi do utraty kontaktów w obrębie trzonowców i przedtrzonowców. Zgodnie z parametrami określonymi przez Kersteina i in. [14] czas od pierwszego kontaktu zębów do maksymalnego zaguzkowania nie powinien przekraczać $0,2 \mathrm{~s}$, a zęby powinny łączyć się synchronicznie i równomiernie. Wydłużenie tego czasu sprzyja nadmiernemu napięciu mięśni żucia, zaburzeniom w obrębie stawu skroniowo-żuchwowego i nadmiernemu obciążeniu zębów i przyzębia. Wykazano istotną statystycznie różnicę ( $p=0,0072)$ pomiędzy czasem okluzji między grupą kontrolną a grupą badawczą. W grupie kontrolnej średni czas był zbliżony do normy i wynosił $0,23 \mathrm{~s}, \mathrm{z}$ maksymalną wartością $0,37 \mathrm{~s}$, natomiast był zdecydowanie dłuższy w grupie badanej i wynosił średnio 0,43 s, z maksymalną wartością $1,18 \mathrm{~s}$. Wydłużenie czasu okluzji może wynikać $z$ istnienia przedwczesnych kontaktów oraz braku stabilności okluzji, a jego skrócenie jest niezbędne do osiągnięcia optymalizacji okluzji. Badana w aparacie T-scan okluzja centralna stanowi pozycję $w$ maksymalnym zaguzkowaniu i występuje za sprawą obustronnie równomiernego skurczu mięśni przywodzących i odwodzących żuchwę. Dzięki temu żuchwa znajduje się w pozycji swobodnego, przyjmowanego odruchowo zwarcia, a jej środek znajduje się w płaszczyźnie strzałkowej [15]. W grupie kontrolnej wszystkie osoby (100\%) charakteryzowały się położeniem środka sił zwarciowych w prawidłowym obszarze, co stanowi istotną statystycznie różnicę $(p=0,0001)$ względem grupy badanej, w której większość pacjentów $(68,18 \%)$ charakteryzowała się położeniem środka sił zwarciowych poza tym obszarem.

\section{Podsumowanie}

W grupie pacjentów z akromegalią na podstawie analizy wybranych parametrów zwarcia możemy zaobserwować brak stabilności okluzji. Sprzyja on występowaniu zaburzeń czynnościowych narządu żucia i może pogłębiać zmiany wynikające z przebiegu choroby. Jest to szczególnie istotne przy rehabilitacji protetycznej tej grupy pacjentów. Leczenie to stanowi bowiem $w$ grupie osób $z$ akromegalią złożony problem, na który wpływ mają zmiany morfologiczne żuchwy, aktywność choroby, ale także zaburzenia czynnościowe, których zbadanie umożliwił aparat T-scan III. Wiadomo, że na siłę zwarcia ma wpływ przede wszystkim aktywność mięśni żucia, a w mniejszym stopniu morfologia szczęk. Liczne badania wykazały związek pomiędzy aktywnością mięśni a parametrami 
zwarcia, a przede wszystkim z jego siłą [16]. Dzięki temu badaniu uzyskujemy dodatkowy czynnik ułatwiający rehabilitację narządu żucia w trudnych przypadkach, do których można zakwalifikować pacjentów z akromegalią. Obiektywne pomiary wykonane za pomocą urządzenia T-scan III mogą zostać włączone w zakres badań przed planowaniem, rozpoczęciem i po zakończeniu leczenia protetycznego.

\section{Wniosek}

Komputerowa analiza zwarcia u pacjentów z akromegalią wykazuje zmiany kontaktów między przeciwstawnymi zębami oraz zmiany rozkładu i zbalansowania sił żucia.

\section{Oświadczenia}

\section{Oświadczenie dotyczące konfliktu interesów}

Autorzy deklarują brak konfliktu interesów w autorstwie oraz publikacji pracy.

\section{Źródła finansowania}

Autorzy deklarują brak źródeł finansowania.

\section{Piśmiennictwo}

[1] Ruchała M, Szczepanek-Parulska E, Fularz M, Woliński K. Ryzyko rozwoju nowotworów w akromegalii. Wspolczesna Onkol. 2012;16(2):118-124.

[2] likubo M, Kojima I, Sakamoto M, Kobayashi A, Ikeda H, Sasano T. Morphological and histopathological changes in orofacial structures of experimentally developed acromegaly-like rats: an overview. Int J Endocrinol. 2012: ID 254367.

[3] Krysiak R, Okopień B, Marek B. Współczesne poglądy na etiologię, patofizjologię i objawy kliniczne akromegalii. Polski Merkuriusz lekarski, Medpress. 2012, tom XXXII, nr 188, luty, 123-128.

[4] Ho JP, Fig LM, Barkan AL, Shapiro B. Bone Mineral Density of the Axial Skeleton in Acromegaly. J Nucl Med. 1992;33:1608-1612.

[5] Bolanowski M, Daroszewski J, Mędraś M, ZadrożnaŚliwka B. Bone mineral density and turnover in patients with acromegaly in relations to sex, disease activity and gonadal function. J Bone Miner Metab. 2006;24:72-78.

[6] Killinger Z, Kužma M, Sterančáková L, Payer J. Osteoarticular changes in acromegaly. Int J Endocrino.; 2012: ID 839282.
[7] Dostálová S, Šonka K, Šmahel Z, Weiss V. Marek J. Cephalometric assessment of cranial abnormalities in patient with acromegaly. J Craniomaxillofac Surg. 2003;31:80-87.

[8] Montgomery M. T-Scan Dental Force Analysis for Routine Dental Examination. Dentistry Today. 2011 July;7(30): 112-116.

[9] Gala A, Pihut M, Majewski S. Uwagi praktyczne dotyczące instrumentalnej analizy zwarcia. Implantoprotetyka. 2011;1-2(XII):42-43.

[10] Qadeer S, Kerstein R, Kim RJY, Huh J, Shin S.Relationship between articulation paper mark size and percentage of force measured with computerized occlusal analysis. J Adv Prtosthodont. 2012 Feb;4(1):7-12.

[11] Kerstein RB, Grundset K. Obtaining Bilateral Simultaneous Occlusal Contacts With Computer Analyzed and Guided Occlusal Adjustments. Quintessence Int. 2001;32: 7-18.

[12] Gala A, Pihut M, Wiśniewska M, Majewski S. Ocena rozkładu kontaktów okluzyjnych u pacjentów z pojedynczymi brakami uzębienia - doniesienie wstępne. Dental Forum. 2014;1(XLII):37-41.

[13] Pihut M. Czynniki wpływające na siły zgryzowe generowane w układzie stomatognatycznym. Poradnik Stomatologiczny. 2013;9:20-23.

[14] Kerstein RB.Reducing chronic masseter and temporalis muscular hyperactivity with computer-guided occlusal adjustments. Compend Contin Educ Dent. 2010;31(7): 530-534.

[15] Majewski SW. Gnatofizjologia stomatologiczna. Normy okluzji i funkcje układu stomatognatycznego.Warszawa PZWL 2007, wyd. I. rozdz. 5 Fizjologiczne normy i typy okluzji, str. 96-103.

[16] Raadsheer MC, Van Eijden T, Van Ginkel F, PrahlAndersen B. Contribution of jaw muscle size and craniofacial morphology to human bite force magnitude. J Dent Res. 1999;78:31-42.

Zaakceptowano do edycji: 2017-09-12 Zaakceptowano do publikacji: 2017-11-22

Adres do korespondencji: Ryszard Koczorowski Klinika Gerostomatologii i Patologii Jamy Ustnej Collegium Stomatologicum UMP ul. Bukowska 70, 60-812 Poznań tel.: +48 618547050 e-mail: rkoczor@ump.edu.pl 